\title{
Cooling Rate, Hardness and Microstructure of Aluminum Cast Alloys
}

\author{
Hasan Akhyar', Ahmad Farhan ${ }^{2}$ \\ ${ }^{1}$ Department of Mechanical, Syiah Kuala University, Jl. Syech Abdurrauf No. 7, Darussalam, Banda Aceh 23111, Indonesia \\ ${ }^{2}$ Department of Physic Education, FKIP Syiah Kuala University
}

\begin{abstract}
This experiment investigated the cooling curve behavior, hardness and microstructure of two aluminum alloys produced by casting process. There are Al-1.37Zn-1.19Si and Al-1.66Si-1.35Zn derived from melting and alloying a pure aluminum with ADC12 (Al-Si) ingot. Cooling curve recorded from both those two alloys with pouring temperature at $710 \mathrm{oC}$ and the mold temperature kept constant at $220 \mathrm{oC}$. The result shows, a freezing range of Al-1.37Zn-1.19Si alloy is $643-348 \mathrm{oC}$ and Al-1.66Si-1.35Zn alloy is 621-401 oC. Then cooling rate obtained for Al-1.37Zn-1.19Si is $55.56 \mathrm{oC} / \mathrm{S}$, and $\mathrm{Al}-1.66 \mathrm{Si}-1.35 \mathrm{Zn}$ is $30.09 \mathrm{oC} / \mathrm{S}$. TThe higher hardness is $40.42 \mathrm{BHN}$ at $\mathrm{Al} 1.66 \mathrm{Si}-1.35 \mathrm{Zn}$, while the lower value is $34.62 \mathrm{BHN}$ on $\mathrm{Al}-1,37 \mathrm{Zn}-1,19 \mathrm{Si}$ alloy. The hardness value found higher when cooling rate is shorted. The number of silicon present on microstructure is highest in Al-1.37Zn-1.19Si alloy but the hardness value decreases. This is caused by the distribution of the silicon content in the alloy is irregular. It was found that the solidification rate had an effect on hardness, where the freezing rate obtained a high hardness value.
\end{abstract}

Keywords: Metal casting; metallurgy; cooling curve; cooling rate; aluminum alloy; hardness

\section{Introduction}

Aluminum alloys have widely used in automotive manufacturing, aerospace component manufacturing and advanced military applications ${ }^{[1]}$. They have a high strength to weight ratio, excellent castability, high corrosion resistance, low coefficient of thermal expansion, and good wear resistance ${ }^{[2]}$. Metal casting is a process for fabricating structure components, but a disadvantage of this technique is lower mechanical properties than base material before melted. Pouring temperature is one of the casting parameters that affecting on material properties ${ }^{[3]}$. Foundry variable such as mold material and pouring temperature has affected on increasing casting quality of LM25 aluminum alloy ${ }^{[4]}$. Study on the impact of cooling rate on solidification behavior in casting Mg-10Gd-3Y-0.4Zr alloy using sand mold has been done ${ }^{[5]}$. The influence of cooling rate on mechanical properties of aluminum alloys has been widely investigated ${ }^{[6,7]}$. Study on a cooling curve during solidification and hardness during recycled Al-Zn aluminum alloy by metal casting process has been done ${ }^{[8]}$. The effect of cooling rate on microstructure and solidification parameter of $\mathrm{Al}-7 \mathrm{Si}-0.3 \mathrm{Mg}-0.15 \mathrm{Fe}$ alloy was investigated ${ }^{[9]}$, the result shows hardness enhances with the increased cooling rate.

Influence of mischmetal as a modifier, heat treatment and cooling rate on hardness properties of non-modified and modified by Sr for A319.1, A356.2 and A413.1 as-cast alloys has been studied ${ }^{[10]}$. There are two cooling rates were used to estimate hardness levels ( $\sim 85$ and $\sim 110-115 \mathrm{BHN})$ in commercial alloys. The result displayed hardness indexes were higher at high cooling rates if compared with low cooling rates of the as-cast alloys. Non-modified or no $\mathrm{Sr}$ addition alloys showed slightly higher hardness levels beside the Sr modified alloys, and the hardness index also decreased with added mischmetal for both cooling rates. An interaction between mischmetal with the alloying elements $\mathrm{Cu}$ and $\mathrm{Mg}$ were forming the various intermetallic phases may be attributed reducing the hardness values. Increasing of those elements followed by decreasing the formation volume fraction of the precipitation-hardening phases $(\mathrm{A} 12 \mathrm{Cu}$ and

Copyright (C) 2018 Hasan Akhyar et al.

doi: $10.18063 / \mathrm{msmr} . \mathrm{v} 2 \mathrm{i} 1.354$

This is an open-access article distributed under the terms of the Creative Commons Attribution Unported License

(http://creativecommons.org/licenses/by-nc/4.0/), which permits unrestricted use, distribution, and reproduction in any medium, provided the original work is properly cited. 
Mg2Si phases) on the A319.1 and A356.2 alloys, subsequently reducing the hardness.

The Cooling Curve Analysis (CCA) method can predict microstructure, grain refinement, and determine the latent heat of solidification ${ }^{[1]]}$. The solidification of metal alloys can be observed through Computer-Aided Cooling Curve Analysis (CA-CCA). It can determine thermo-physical properties of metal alloys, latent heat from solidification ${ }^{[12,13]}$. Al-Si-Zn alloy has been applied to filler on brazing joint the 6061 aluminum alloy, and as sprayer on a plaster substrate ${ }^{[14-16]}$. The main objective of this experiment is to investigate the cooling curve behavior, microstructure and hardness on $\mathrm{Al}-1.37 \mathrm{Zn}-1.19 \mathrm{Si}$ and $\mathrm{Al}-1.66 \mathrm{Si}-1.35 \mathrm{Zn}$ during solidification. The study was divided into two parts, the first part was observed cooling rate when the solidification of Al-1.37Zn-1.19Si and Al-1.66Si-1.35Zn alloys. The second part is to observe the microstructure and hardness in both materials.

\section{Materials and Methods}

\subsection{Material}

Al-1.37Zn-1.19Si and Al-1.66Si-1.35Zn alloys were prepared by casting metallurgy pro-cess. Pure aluminum and ADC12 were taken as the starting raw material as shown in Table 1. The chemical composition of the alloys, analyzes by spectroscopy' s metal standard. The chemical compositions (wt.\%) of the alloys used in this experiment are shown in Table 2.

\begin{tabular}{|l|l|l|l|l|l|l|l|l|l|l|l|}
\hline Alloy & Si & Fe & Cu & Mn & Ti & Cr & Pb & Sn & Ni & Zn & Al \\
\hline Pure Al & 0.24 & 0.53 & 0.13 & 0.07 & 0.01 & 0.004 & 0.7 & 0.01 & 0.007 & 1.65 & 97.26 \\
\hline ADC12 & 10.56 & 0.78 & 1.71 & 0.15 & 0.02 & 0.029 & 0.05 & 0.19 & 0.05 & 0.83 & 85.6 \\
\hline
\end{tabular}

Table 1. Base materials used for alloying metal (wt.\%)

\begin{tabular}{|l|l|l|l|l|l|l|l|l|l|l|}
\hline Alloy & $\mathrm{Si}$ & $\mathrm{Fe}$ & $\mathrm{Cu}$ & $\mathrm{Mn}$ & $\mathrm{Mg}$ & $\mathrm{Ti}$ & $\mathrm{Cr}$ & $\mathrm{Ni}$ & $\mathrm{Zn}$ & $\mathrm{Al}$ \\
\hline Al-1.37Zn-1.19Si & 1.19 & 0.62 & 0.3 & 0.06 & 0.01 & 0.02 & 0.006 & 0.009 & 1.37 & $\mathrm{Bal}$. \\
\hline Al-1.66Si-1.35Zn & 1.66 & 0.71 & 0.39 & 0.07 & 0.01 & 0.02 & 0.008 & 0.011 & 1.35 & Bal. \\
\hline Al-2.81Zn-2.6Si & 2.6 & 1.41 & 0.87 & 0.09 & 0.01 & 0.02 & 0.013 & 0.029 & 2.81 & Bal. \\
\hline
\end{tabular}

Table 2. Chemical composition of cast-sample (wt\%)

\subsection{Methods}

Induction furnace used for melting aluminum alloys and cast into a permanent mold with the diameter is $9.5 \mathrm{~mm}$. A steel mold was preheated with temperature of $220 \mathrm{oC}$. Temperature release from molten to air was recorded. A thermocouple K-type was inserted into steel mold for recording cooling temperature during solidification of $\mathrm{Al}-1.37 \mathrm{Zn}-1.19 \mathrm{Si}$ and $\mathrm{Al}-1.66 \mathrm{Si}-1.35 \mathrm{Zn}$ alloys with pouring temperature at $710 \mathrm{oC}$. The cast samples were grind using $\mathrm{SiC}$ paper and polished using a standard technique. Hardness value from the alloys was performed using a Brinell test on a section perpendicular of cast sample with five point indentations (Figure 1). The diameter of the ball indentor is 2.5 $\mathrm{mm}$, the load is applied at $249 \mathrm{~N}$, and the indentation time is 30 seconds. Hardness value is obtained from the general formula $\mathrm{BHN}^{[4]}$.

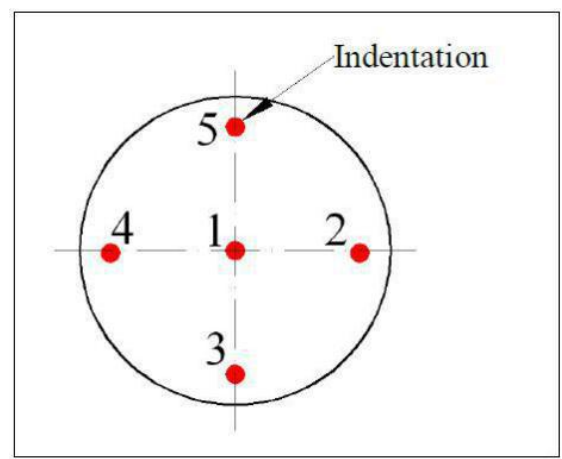

Figure 1; Five location indented on cross section of cast-sample. 


\section{Results and Discussion}

\subsection{Cooling Curve/Rate}

Figure 2 and Figure 3 show cooling and first derivative curve on Al-1.37Zn-1.19Si and Al-1.66Si-1.35Zn alloys for pouring temperature at $710 \mathrm{oC}^{[17]}$. The solidification curves indicate that thermocouples data recorded from a particular range of Solidification. The first peak of derivatives curve shows the liquidus temperature about $643 \mathrm{oC}$ (primary $\alpha-\mathrm{Al}$ formation). The second peak on derivatives curve denotes the solidus temperature around $348 \mathrm{oC}$. The liquidus temperature is $621 \mathrm{oC}$, and the solidus temperature is $401 \mathrm{oC}$ from cooling and first derivative curve with pouring temperature at $710 \mathrm{oC}$ on $\mathrm{Al}-1.66 \mathrm{Si}-1.35 \mathrm{Zn}$ alloy, as shown in Figure 3. The freezing range for $\mathrm{Al}-1.37 \mathrm{Zn}-1.19 \mathrm{Si}$ with casting temperature at $710 \mathrm{oC}$ ranges about $643-348 \mathrm{oC}$ and freezing range for $\mathrm{Al}-1.66 \mathrm{Si}-1.35 \mathrm{Zn}$ with pouring temperature at $710 \mathrm{oC}$ ranges from 621 to $401 \mathrm{oC}$. Cooling rate for Al-1.37Zn-1.19Si is $55.56 \mathrm{oC} / \mathrm{S}$ and $\mathrm{Al}-1.66 \mathrm{Si}-1.35 \mathrm{Zn}$ is $30.09 \mathrm{oC} / \mathrm{S}$. Cooling rate as a thermodynamic parameter is significantly affected by the pouring temperature, and it would decrease with increasing of pouring temperature ${ }^{[5]}$.

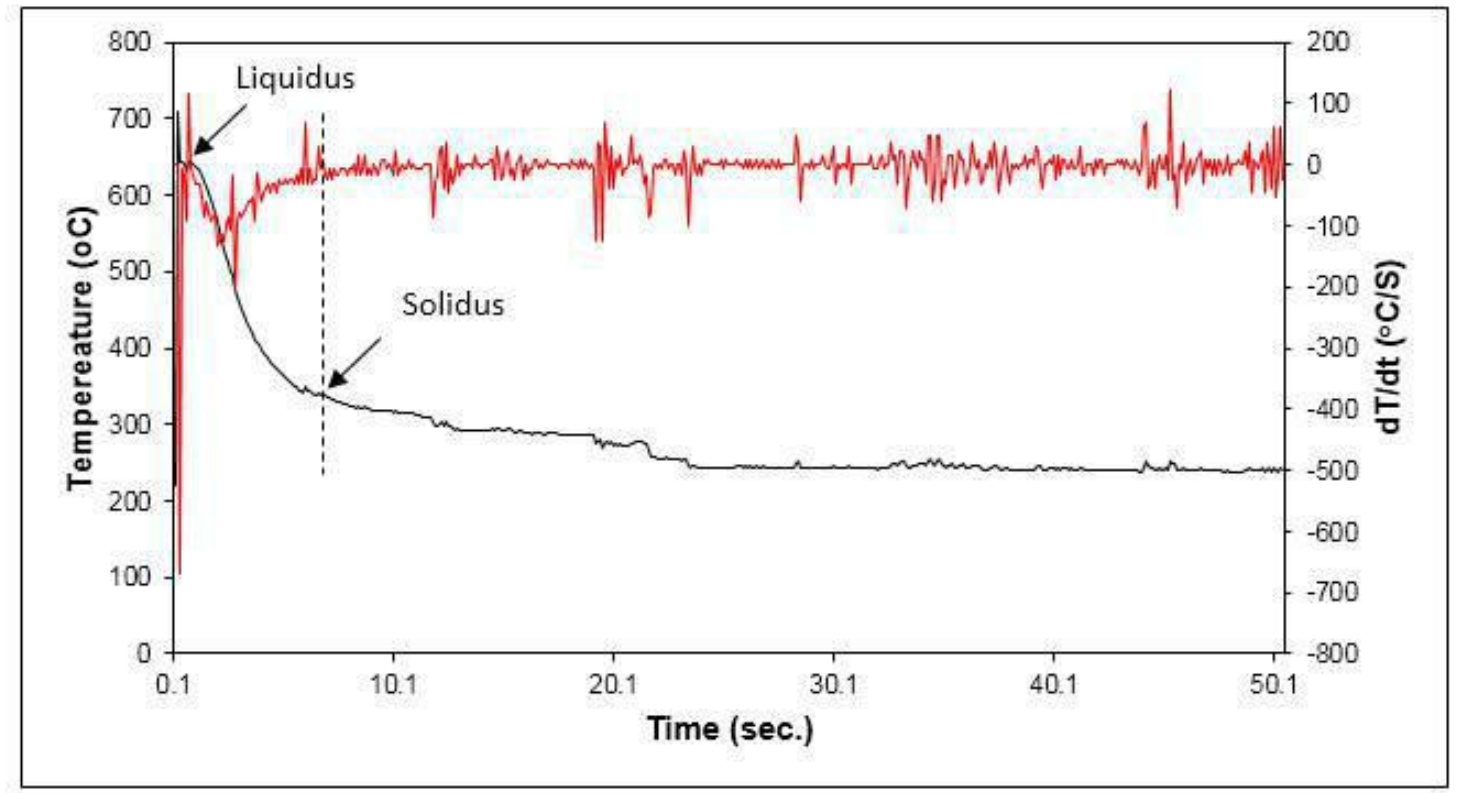

Figure 2; Cooling curves and the first derivative on Al-1.37Zn-1.19Si alloy with poured at $710{ }^{\circ} \mathrm{C}$.

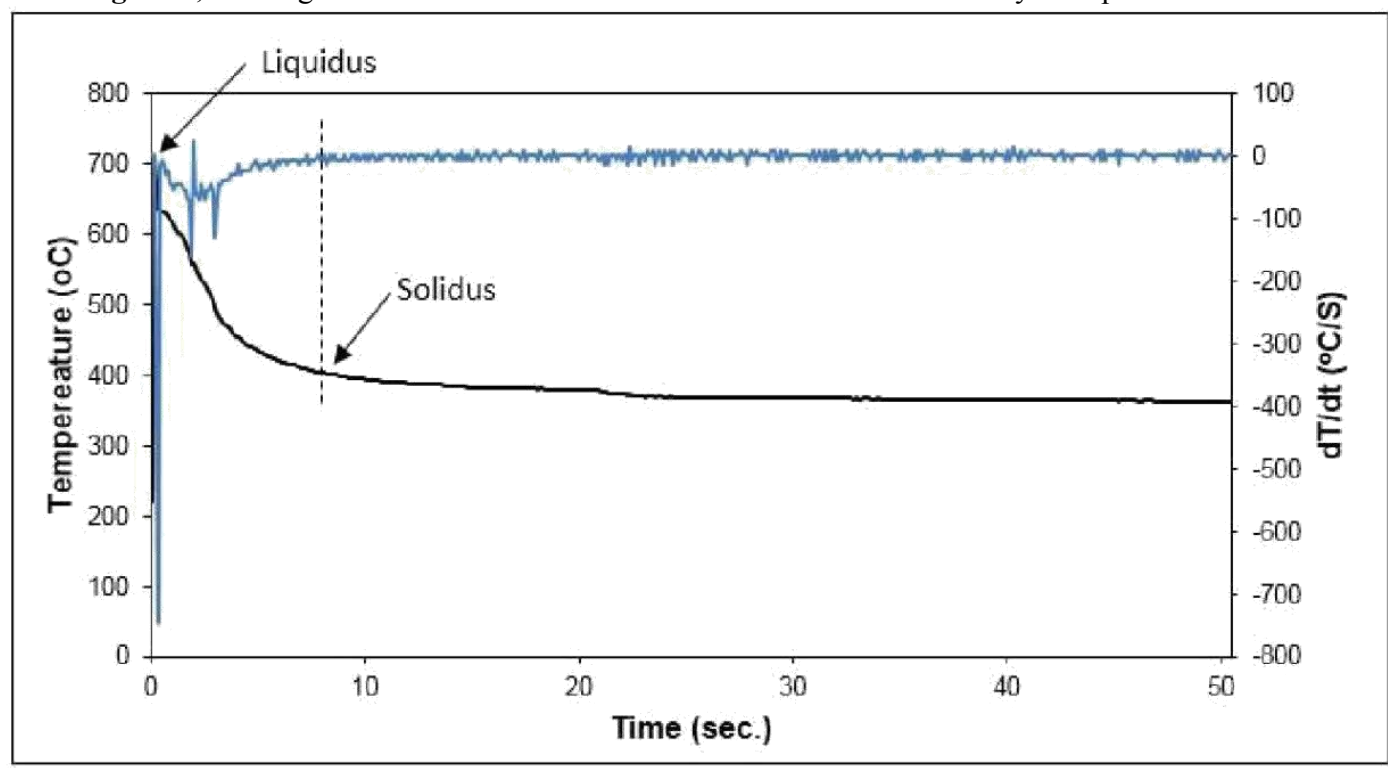

Figure 3; Cooling curves and the first derivative on Al-1.66Si-1.35Zn alloy with poured at $710{ }^{\circ} \mathrm{C}$. 


\subsection{Hardness and Microstucture}

Hardness properties of the cast-sample were observed, it shown in Figure 4. The higher hardness value presented on Al-1.66Si-1.35Zn alloy is 40.42 BHN. The Al-1.37Zn-1.19Si alloy has lower index, it is 36,2 BHN. Primary silicon appear in Al-1.66Si-1.35Zn alloy spread evenly on the entire surface of microstructure, while for Al-1.37Zn-1.19Si primary silicon present alloy accumulate in the middle of microstructure Figure $5 \mathrm{a}^{[18]}$. Hardness values also seen higher in Al-1.66Si-1.35Zn alloys when compared with to Al-1.37Zn-1.19Si alloys, this is influenced by the silicon distribution in cast-sample. The percentage amount of silicon on microstrcuture is obtained with the highest value in Al-1.37Zn-1.19Si alloys through calculated by using ImageJ Software (Table 3). The freezing rate of the Al-1.66Si-1.35Zn alloy is shorter so that the hardness value is high in the alloy. The hardness increase in alloy with increasing cooling rate during solidification. Hardness average value is rising from $490 \mathrm{Hv}$ at slow cooling rates to 520 Hv for metal casting with rapidly cooled. The process of freezing metal alloys was significantly affects to the microstructure and mechanical properties ${ }^{[3]}$. The Influence of cooling rate on Al-18\% aluminum alloy can be affected to the microstructure and material hardness. High Solidification rate causes microstructure more finer. High solidification rate is seen to affect the microstructure. Silicon surface area of the material can lead to increasing hardness as seen in the microstructure ${ }^{[7]}$. The freezing range of a metal alloy may cause the material to be susceptible to defects, either shrinkage porosity or hot tearing defects ${ }^{[6]}$.

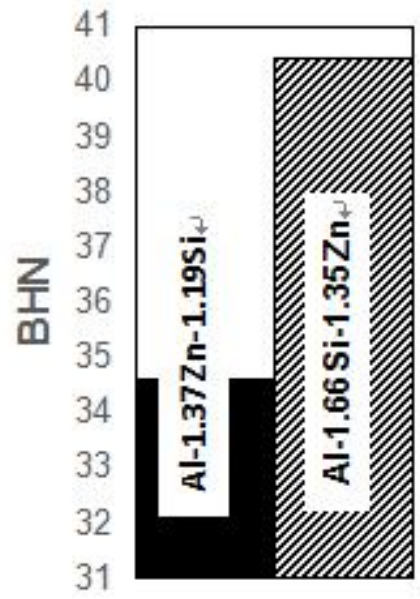

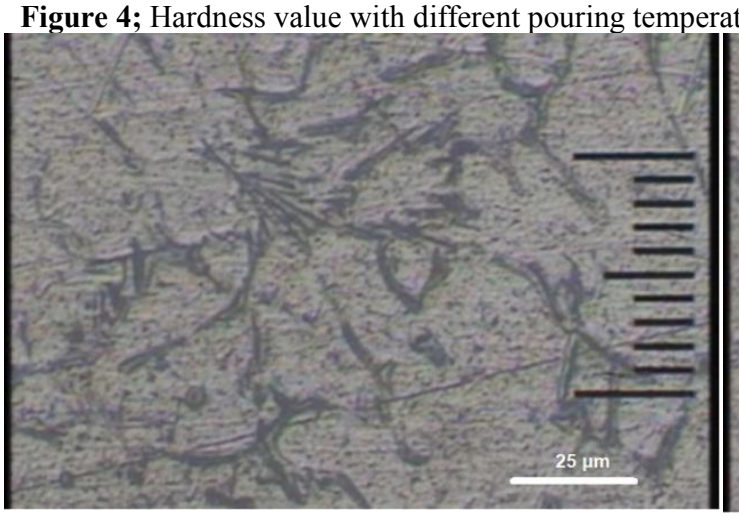

(a)

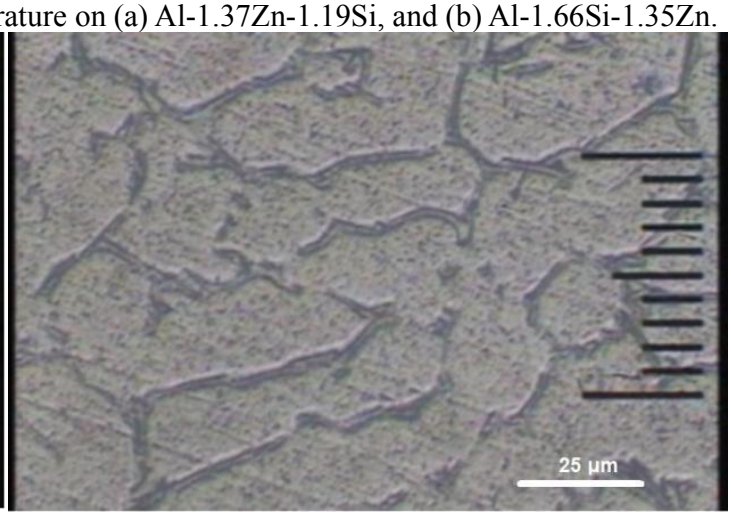

(b)

Figure 5; Microstructure of cast-sample, (a) Al-1.37Zn-1.19Si, and (b) Al-1.66Si-1.35Zn

\begin{tabular}{|l|l|l|l|}
\hline Alloys & Primary silicon $\left(\boldsymbol{\mu m}^{\mathbf{2}}\right)$ & Total Area $\left(\boldsymbol{\mu m}^{\mathbf{2}}\right)$ & Silicon $\mathbf{( \% )}$ \\
\hline Al-1.37Zn-1.19Si & $5,838.705$ & $18,549.296$ & 31 \\
\hline Al-1.66Si-1.35Zn & $2,873.405$ & $11,306.744$ & 25 \\
\hline
\end{tabular}

Table 3. Average primary grain surface silicon 


\section{Conclusion}

The conclusion of this experiment show, the freezing temperature of $\mathrm{Al}-1.37 \mathrm{Zn}-1.19 \mathrm{Si}$ is starting from $643 \mathrm{oC}$ until $348 \mathrm{oC}$ with pouring temperature at $710 \mathrm{oC}$, while freezing range of $\mathrm{Al}-1.66 \mathrm{Si}-1.35 \mathrm{Zn}$ is starting with $621 \mathrm{oC}$ to $401 \mathrm{oC}$ at $710 \mathrm{oC}$ of pouring temperature. However, the cooling rate could define for $\mathrm{Al}-1.37 \mathrm{Zn}-1.19 \mathrm{Si}$ is $55.56 \mathrm{oC} / \mathrm{S}$ and Al-1.66Si-1.35Zn is 30.09 oC/S. The higher hardness value presented on Al-1.66Si-1.35Zn alloy is $40.42 \mathrm{BHN}$. The Al-1.37Zn-1.19Si alloy has lower index, it is 36,2 BHN. Short cooling rates produce high hardness values, but silicon content shows low in the Al-1.66Si-1.35Zn alloy. The low silicon content in alloys still shows a high hardness value. According to microstructure indicates that the distribution of silicon content is spread evenly in the alloy, resulting in high hardness values.

\section{Acknowledgement}

This publication was made possible by a Grant from the Indonesia National Research Fund (No.:090/UN11.2/LT/SP3/2015; No.: 035/SP2H/PL/Dit.Litabmas/II/2015); the financial support is greatly appreciated. We would like to thank Dr. Suyitno and Prof. Husaini for support during this research. Part of this article has been presented at The International Conference on Engineering and Research and Development (ICESReD 2016), at Syiah Kuala University - Banda Aceh, Indonesia.

\section{Reference}

1. Wang, H.J., Xu, J., Kang, Y.L., Tang, M.O. and Zhang, Z.F. (2014) Effect of Al-5Ti-1B-1Re on the Microstructure and Hot Crack of As-Cast Al-Zn-Mg-Cu Alloy. Journal of Materials Engineering and Performance. 23(4): 2014-1165.

2. Fang, H.C., Chao, H., Chen, K.H. (2014) Effect of $\mathrm{Zr}$,Er and $\mathrm{Cr}$ additions on microstructures and properties of $\mathrm{Al}-\mathrm{Zn}-\mathrm{Mg}-\mathrm{Cu}$ alloys. Materials Science \& Engineering A, 610: 10-16.

3. Kaiser, R., Williamson, K., O’brien, C. and Browne, D.J. (2013) Effects of Section Size, Surface Cooling Conditions, and Crucible Material on Microstructure and As-Cast Properties of Investment Cast Co-Cr Biomedical Alloy. Metallurgical and materials transactions A. 44A: 2013-5333.

4. Kabir M.S., Ashrafi A.A., Minhaj T. I., Islam M.M. (2014) Effect of Foundry Variables on the Casting Quality of As-Cast LM25 Aluminum Alloy, International Journal of Engineering and Advance Technology, 3(6): 115-120.

5. Pang S., Wu G., Liu W., Zhang L., Zang Y., Conrad H., Ding W. (2015) Influence of pouring temperature on solidification behavior, microstructure and mechanical properties of sand-cast $\mathrm{Mg}-10 \mathrm{Gd}-3 \mathrm{Y}-0.4 \mathrm{Zr}$ alloy, Trans. Nonferrous Met. Soc. China, 25: 363-374.

6. Amin K.M., Mufti N.A (2012) Investigating cooling curve profile and microstructure of a squeeze cast $\mathrm{Al}-4 \% \mathrm{Cu}$ alloy", Journal of Materials Processing Technology, 212: 1631- 1639.

7. Akili C.E, Alami M., Bouatad A. (2014) Cooling Rate Effect Study on the Microstructure and Hardness of Hypereutectic Aluminum Al-18\%Si Elaborated by V-process, International Journal of Engineering Trends and Technology, 7(2).

8. Akhyar H., Husaini, (2016) Study on Cooling Curve Behavior During Solidification and Investigation of Impact Strength and Hardness of Recycled Al-Zn Aluminum Alloy, International Journal of Metalcasting, doi: 10.1007/s40962-016-0024-8.

9. Pang, S., Wu, G., Liu, W., Sun, M., Zhang, Y., Liu, Z., Ding, W. (2013) Effect of cooling rate on the microstructure and mechanical properties of sand-casting $\mathrm{Mg}-10 \mathrm{Gd}-3 \mathrm{Y}-0.5 \mathrm{Zr}$ magnesium alloy. Materials Science \& Engineering A, 562: 152-160.

10. Sebaie, O.E., Samuel, A.M., Samuel, F.H., Doty, H.W. (2008) The effects of mischmetal, cooling rate and heat treatment on the hardness of A319.1, A356.2 and A413.1 Al-Si casting alloys. Materials Science and Engineering A 486: 241-252.

11. Dehnavi, M., Haddad-Sabzevar, M., Avazkonnadeh-Gharavol, M.H. (2015) Cooling Curve Analysis in Binary Al-Cu Alloys: Part II- Effect of Cooling Rate and Grain Refinement on The Thermal and Thermodynamic Characteristics, Metall. Mater. Eng. Vol 21 (3): 207-221.

12. Dehnavi, M., Kuhestani, F., Haddad-Sabzevar, M., (2015) Cooling Curve Analysis in Binary Al-Cu Alloys: Part IEffect of Cooling Rate and Copper Content on The Eutectic Formation, Metall. Mater. Eng. Vol 21 (3): 195-205.

13. Ihsan-ul-haq, Shin, J., Lee, Z., (2004) Computer-Aided Cooling Curve Analysis of A356 Aluminum Alloy, METALS AND MATERIALS International, Vol. 10, No. 1: 89-96.

14. Dai, W., Xue, S., Lou, J. Wang, S., (2012) Microstructure and Properties of 6061 Aluminum Alloy Brazing Joint with AlSiZn Filler Metal, Materials Transactions, Vol. 53(9): 1638-1643. 
15. Maruyama, T., Kobayashi, T., Kano, M., (2006) A Spray Coating and Its Mechanical Properties of Al-Si-Zn Alloy Produced by the Spray Forming Process, Materials Transactions, Vol. 47(7): 1853-1858.

16. Dai, W., Xue, S., Ji, F., Lou, J., Sun, B., Wang, S., (2013) Brazing 6061 aluminum alloy with Al-Si-Zn filler metals containing Sr, International Journal of Minerals, Metallurgy and Materials, Vol. 20(4): 365-369.

17. Akhyar, H., Farhan, A., (2016) Cooling Rate Investigation and the Influence of Pouring Temperature on Hardness Properties of As-Cast Aluminum Alloys, Proceedings of International Conference on Engineering and Science for Research and Development (ICESReD) 2016, October 25-26, 2016, Banda Aceh, Indonesia.

18. Akhyar, H., Malau, V., Suyitno, Iswanto, P.T., (2017) Hot tearing susceptibility of aluminum alloys using CRCM-Horizontal mold, Results in Physics, Vol. 7: 1030-1039. 